\title{
Ekip Çalışması ve Profesyonel Özerklik Uyumlu mu ve İyileştirilmiş Hastane Bakımı ile Sonuçlanıyor Mu?
}

\author{
Muhammet GÜMÜŞ \\ Yüksek Lisans Öğrencisi, Sivas Cumhuriyet Üniversitesi, muhammetgumus5208@ gmail.com \\ ORCID: 0000-0003-1278-6234 \\ Sibel ORHAN \\ Yüksek Lisans Öğrencisi, Tekirdağ Namık Kemal Üniversitesi, sibelorhan09@gmail.com \\ ORCID: 0000-0002-2892-3865
}

\author{
Ayșenur CEYLAN \\ Yüksek Lisans Öğrencisi,Kahramanmaraş Sütçü İmam Üniversitesi, \\ aysenurceylan38@gmail.com \\ ORCID: 0000-0002-2103-8353 \\ Emine KIZILKAYA \\ Yüksek Lisans Öğrencisi,Karamanoğlu Mehmet Bey Üniversitesi, \\ emine_kizil_37@hotmail.com \\ ORCID: 0000-0002-3678-0905
}

\section{ÖZET}

Disiplinler arası ekip çalışması ile hasta ve hemşire özerkliği arasındaki ilişkiyi araştırmak için, Türkiye'de 32 hastanede 10.022 hemşirenin katıldığ bir çevrimiçi anket araştırması yapılmıştır ve hemşire bakım kalitesi değerlendirilmiştir. Hemşirelik özerkliği, kaynakları üzerinde kontrol, doktorlarla ilişki, duygusal tükenme ve karar vermenin temel değişkenlerinin birbirleriyle ilişkili olduğu ve aynı zamanda hemşire ile değerlendirilen bakım kalitesi ve hemşire memnuniyeti ilişkisinin olduğu bulunmuştur. Hemşirelik özerkliği, sunulan hizmetin kalitesinin daha iyi algılanması ve daha yüksek iş tatmini seviyeleri ile pozitif olarak ilişkilendirilmiştir. Ekip çalışmasının iş özelliklerine göre analizi, tam zamanlı ve yarı zamanlı hemşireler arasında ekip çalışması düzeyinde küçük ama anlamlı bir fark olduğunu göstermiştir. Sözleşme türüne (kalıcı ve kısa vadeli), servis / birimin uzmanlığı, vardiya uzunluğu veya iş unvanına göre önemli farklılıklara rastlanmamıştır. Ekip çalışması puanları daha yüksek olan hemşirelerin işlerinden memnun olma olasılı̆̆ı, işlerinde kalmayı planlama ve tükenmişlik puanları önemli ölçüde daha yüksektir. Daha yüksek ekip çalışması puanları, daha yüksek hemşire tarafından değerlendirilen bakım kalitesi, geçen yıl algılanan kalite artışı ve hastaların taburcu olduklarında bakımlarını yönetebileceklerine dair güven ile ilişkilendirilmiştir. Ekip çalışması puanları daha yüksek olan hemşireler de, daha yüksek düzeyde özerklik ortaya çıkmıştır ve karar verme sürecine daha fazla dâhil olmuşlardır. Ekip çalışması ile özerklik arasında güçlü bir ilişki bulunmaktadır; bu etkileşim, çatışmadan çok

Year 5/ 2021, Volume-5, Issue-2 | www.ispecjournal.org

1. This study presented orally in the BILTEK International Symposium-IV; held on April 12-13, 2021 at Gaziantep University, Nizip Faculty of Education, Gaziantep, Turkey. 
sinerjiyi akla getirmiştir. Bu nedenle kuruluşlar, ekip çalışmasına zarar verebileceğinden, korkmadan hemşire özerkliğini teşvik etmektedir.

Anahtar Kelimeler: Ekip Çalışması, Hemşirelik Özerkliği, Meslekler Arası Çalışma, Bakım Kalitesi.

\title{
Is Teamwork and Professional Autonomy Compatible and Result in Improved Hospital
}

\section{Care?}

\begin{abstract}
To investigate the relationship between patient and nurse interdisciplinary teamwork with autonomy, an online survey in which 10,022 nurses in 32 hospitals participating in Turkey are made and evaluated the quality of nursing care. It was found that the basic variables of nursing autonomy, control over resources, relationship with doctors, emotional exhaustion and decision-making were correlated with each other, as well as the quality of care assessed with nurses and nurse satisfaction. Nursing autonomy has been positively associated with better perception of the quality of service provided and higher levels of job satisfaction. Analysis of teamwork by job characteristics showed that there is a small but significant difference in teamwork level between full-time and part-time nurses. There were no significant differences in terms of contract type (permanent and short term), service / unit's expertise, shift length or job title. Nurses with higher teamwork scores are significantly more likely to be satisfied with their jobs, planning to stay in their jobs, and burnout scores. Higher teamwork scores were associated with higher nurse-assessed quality of care, perceived quality improvement over the past year, and patients' confidence that they could manage their care upon discharge. Nurses with higher teamwork scores also resulted in higher levels of autonomy and were more involved in the decision-making process. There is a strong relationship between teamwork and autonomy; this interaction suggested synergy rather than conflict. Therefore, organizations encourage nurse autonomy without fear, as it can undermine teamwork.
\end{abstract}

Key words: Teamwork, Nursing Autonomy, Interprofessional Work, Quality of Care.

\section{GİRIŞ}

Sağlık hizmetlerinin karmaşıklığı, nüfusun yaşlanması, biyomedikal gelişmelerin olması, günlük sorunların tıbbileştirilmesi sonucu son yirmi yılda maliyet kontrol faaliyetlerinde artış olduğu görülmektedir. Buna bağlı olarak hemşirelerin, doktorların ve diğer sağlık personellerinin sorumlulukları artmıştır. Meslekler arasındaki sınırların karmaşıklaştığı, profesyoneller ile diğer sağlı çalışanları ve yönetim kademeleri arasındaki karşılıklı bağımlılık ihtiyacının arttığı görülmektedir (Mechanic,1982). Aynı zamanda, sağlık profesyonelleri, özerkliklerindeki işlerinden duydukları memnuniyeti zayıflatır, iş devir hızı artışı sağlar ve bu bağlamda istikrarsız, hoşnutsuz çalışan personeller görülür. Son on yıl içinde yöneticiler, profesyonel özerklik yerine ekip çalışmasını vurgulayan üretim

Year 5/ 2021, Volume-5, Issue-2 | WWW.ispecjournal.org

1. This study presented orally in the BILTEK International Symposium-IV; held on April 12-13, 2021 at Gaziantep University, Nizip Faculty of Education, Gaziantep, Turkey. 
örneklerinden yararlanmışlardır ve bu nedenle, sağlık hizmetlerinin yeniden yapılandırılması için verimlilik modellerine ilgi gittikçe artmaktadır. Bu girişimlerin birçoğunda, daha verimli veya etkili bakım üretmekte başarısız olunduğu görülmüştür. Ekip çalışmasında kötü bir izlenim yaratmıştır, özellikle de ekipleri içeren yeniden yapılanmanın yönetsel yetkileri ile onların kötüleşen çalışma koşulları arasında bir ilişki olduğu görülmektedir (Leatt \& Aiken 1997-2000).

Bununla birlikte, sağlık hizmetlerinde kötü bir hata ile karşılaşıldığında, disiplinler arası iletişimin başarısızlığı sonucu ile karşı karşıya kalınmaktadır. Cerrahların çok etkili bir ekip çalışmasına sahip oldukları görülmektedir, ancak, onlar bir ekibin bir parçası olmaktan ziyade yönettikleri takımların üyeleridirler. Benzer şekilde, "takımlar" çok profesyonel olmaktan ziyade aynı branşların arasında son derece hiyerarşik bir durum olduğu görülmektedir. Hemşireler ve doktorlar arasındaki gerginlikler ve meslekler arası ekip çalışmasının önündeki engeller hatırı sayılır yorumlara yol açmaktadır (Stein 1967-1990,Casey 1997). Aslında, iş bölümü içindeki eşitsizlikler, piramidin en üst noktasında bulunan doktorlar ile iktidar ilişkilerindeki eşitsizlikleri yönetmektir(Wicks vd., 1998). Hemşireler ve doktorlar arasındaki otorite ve yargı sınırları konusunda ilk anlaşmazlıklardan başlayarak, meslekler arası çatışmaların uzun bir geçmişinin olduğu görülmektedir (RaVerty,1996). Toplumsal cinsiyet karşıtlığnın genellikle bunun kökeninde yer aldığı görülmektedir. Walby ve arkadaşları tarafından yapılan çalışmalarda, 400'den fazla anlaşmazlığın olduğu tespit edilmiştir (Walby vd.,1994). Tıp ve hemşirelik çalışmalarının deney aşamasında, bir çatışma kategorisi olduğu görülmektedir. Yöneticilerle ilişkiler de sorunlu olarak görülmekte ve doğası gereği karşı olarak nitelendirilmektedir (Strang vd., 1990 \& Traynor, 1999) .

Anahtar Mesajlar

- Hemşireler tarafından değerlendirilen bakım kalitesi üzerinde bildirilen daha yüksek düzeyde ekip çalışmasının etkisinin olduğu,

- Ekip çalışması ile özerklik arasında güçlü bir ilişki bulunması,

- Kuruluşlar hemşire özerkliğini teşvik edebilir ve ekip çalışmasını geliştirebilirler.

Sağlık hizmetleri karmaşıktır ve birçok kesişen baskılarla karşı karşıyadır. İş bölümünün doğası, yapısal güç ilişkilerinin karmaşık kesişimi neredeyse kaçınılmaz olarak tartışma ve görüşme alanı olduğu anlamına gelmektedir.

Profesyonel çalışma birbirine bağımlı ve bağımsız unsurları içermektedir ( Irvine vd.,1998). Abbott'un bu ilişki matrisini, her mesleğin yargı bağları tarafından bir dizi görevle uyumlu Year 5/ 2021, Volume-5, Issue-2 | WWW.ispecjournal.org 
olduğu mesleklerin "sistem"inde kabul ettiği görülmektedir (Abbott, 1998). Bu iddialar kamuya açık, meşru ve iş yeri bağlamlarında yapılabilmektedir. İş yerleri içinde, resmileştirilmiş iş tanımları sadece iş içeriğine ilişkin olarak resimleştirilirken, işbölümü özel bir ürün olarak görülmekte ve kararlaştırılmış bir sipariş olarak bilinmektedir (Allen,2001). Görüşme kararının çoğu, resmi ve kamusal mesleki görevlerini özel ve yerel uygulamalara “çeviren” profesyoneller tarafından yapılmaktadır.

\section{TAKIM ÇALIŞMASININ DEĞERLENDİRILMESI}

Ekip çalışmasının değeri sezgisel bir çekiciliğe sahipken, örgütsel süreçler ve sonuçlar üzerindeki etkisinin daha zor olduğu bilinmektedir. Ekip çalışması için talep edilen faydalar arasında şunlar yer almaktadır: Geliştirilmiş finansal sonuçlar, devamsızlık ve azaltılmış personel getirisi, artan personel motivasyonu, yüksek bakım kalitesi, daha iyi hasta sonuçları ve daha az çatışma olarak sıralanabilmektedir (Firth-Cozens,1998-2001). Ekip çalışmasının potansiyel yararları, üyelerin psikolojik sağlığı ve refahı üzerindeki olumlu etkilerden kaynaklanmaktadır (Carter vd.,1999). Birinci basamak ve toplum ruh sağlığının daha düşük stres seviyeleri, daha fazla yenilik, etkinlik ve ekip çalışmasının kalitesiyle ilişkili olduğu bilinmektedir (Borrill vd., 2000).

İkinci basamakta, yoğun bakım üniteleri ekipleri incelemek için zengin bir araştırma ortamı sağlamıştır (Shortell vd., 1994). ABD’deki Shortell vd. yapmış olduğu araştırmada, bir dizi performans göstergesini, mevcut teknoloji seviyesi, hemşire personeli, vaka karışımı, hasta oranları, bakıcı etkileşimi de dâhil olmak üzere bir dizi hipotezi test etmiştir. Bakıcı etkileşimi, beş boyutun birleşik bir ölçüsüdür: İletişim, çatışma, kültür (ortak normlar, beklentiler ve inançlar) ve koordinasyon (yoğun bakım üniteleri ve diğer akut birimleri içinde) liderlik olarak sıralanmaktadır. Yoğun bakım ortamlarının karmaşık sosyo-teknik dinamikleri nedeniyle iletişim özellikle ilgi çekici bir hal almıştır. Özellikle, hemşire devri, bakıcı etkileşimi, vaka karışımına göre ayarlanmış kalış süresi ve "değerlendirilen bakım kalitesi” ve “aile ihtiyaçlarını karşılama yeteneği” ile olumsuz bir şekilde ilişkilendirilmiştir (Zimmerman vd.,1994).Zimmerman vd. tarafından yapılan bir çalışmada, güçlü hemşirelik, daha büyük bir meslektaşlık duygusu ve hasta merkezli kültürle tıbbi liderliğin "üstün organizasyon uygulamaları” ürettiğini iddia ettiği görülmüştür. Doktorlar ve hemşireler arasındaki işbirliğini teşvik etmek için tasarlanmış müdahaleler üzerine yapılan araştırmalar, sağlık hizmetleri süreçlerinde sonuçlardan çok 1lımlı kazanımların mümkün olduğunu

Year 5/ 2021, Volume-5, Issue-2 | WWW.ispecjournal.org

1. This study presented orally in the BILTEK International Symposium-IV; held on April 12-13, 2021 at Gaziantep University, Nizip Faculty of Education, Gaziantep, Turkey. 
göstermektedir (Dechairo-Marino vd., 2001). Zwarenstein ve Bryant araştırmasında bir Cochrane incelemesinde, hastanede kalış süresi ve hastane maliyetleri üzerinde gelişmiş hemşirelik işbirliğinin uyumlu bir etkisini ve mortalite üzerinde fark edilebilir bir fark olmadığını gösteren sadece iki randomize kontrollü çalışmayı tespit etmiştir (Zwarenstein vd., 2001).

\section{ULUSLAR ARASI HASTANE ÇALIŞMASI SONUÇLARI}

Bir dizi çalışma, meslekler arası işbirliğinin olumlu faydalarını işaret etmektedir. Daha iyi hastane sonuçlarına ulaşmak için bir dizi işlemsel mekanizmaları çözmeye çalışırken, hastane sonuçlarıyla ilgili büyük bir uluslar arası çalışmada, çok sayıda örgütsel değişken araştırılmıştır (Sochalski vd., 1997).Uluslar arası hastane sonuçları çalışması, araştırmaya dayalı olarak artan ilgiyi gören "mıknatıs" hastane işgücü organizasyonunun bir yönünden kaynaklanmaktadır. Mıknatıs hastane kavramının, ABD ve İngiltere olmak üzere birçok ülkede potansiyel bir öneme sahip olduğu kabul edilmiştir (Buchan,1994). Mıknatıs hastaneler, ilk olarak 1980'lerin başında hemşirelik personellerinin iş doyumu, hekimlerle ilişkiler ve özerklik konusunda ortalamanın üzerinde ölçülere sahip kurumlar olarak tanımlanmaktadır. Son araştırmalar, ortalama bakım sonuçlarından daha iyi olabileceğini de göstermektedir (Aiken vd., 1994). Ölüm oranları ile mıknatıs hastaneler arasındaki olası bağlantının en ayrıntısı, Aiken vd. tarafından yapılan çalışmada 39 mıknatıs hastane ve 195 kontrol hastanesindeki ölüm oranlarının, hastane özelliklerini kontrol etmek için çok değişkenli eşleştirilmiş örneklem kullanılarak analiz edilmesiyle bulunmuştur. Mıknatıs hastanelerin sağlık sigortası kapsamında olan hastalar için, genel hastanelere göre \%4.6 daha düşük ölüm oranına sahip olduğu görülmektedir. Mıknatıs hastanelerin, diğer hastanelere göre önemli ölçüde daha düşük AIDS ölüm oranına sahip olduğu saptanmıştır (Aiken vd.,1999). Mıknatıs hastanelerin mortalite avantajının yüksek tutulmasının sebebi; daha iyi bir hemşire kadrosuna sahip olması ve profesyonel hemşirelik uygulamalarını destekleyen örgütsel iklim ile ilişkili hizmet veriyor olmasıdır. Mıknatıs hastaneler, daha fazla özerkliğe sahip hemşireler, klinik bakım ortamında daha fazla kontrol ve genel hastanelere kıyasla doktorların daha iyi ilişkilere sahip olmasıyla karakterize edilmiştir. ABD ve diğer ülkelerde hemşirelik bakım organizasyonu, komplikasyonlar ve ölüm oranları arasındaki ilişki üzerine daha fazla araştırma çalışması yapılmaktadır (Sochalski vd.,1997).

Year 5/ 2021, Volume-5, Issue-2 | WWW.ispecjournal.org

1. This study presented orally in the BILTEK International Symposium-IV; held on April 12-13, 2021 at Gaziantep University, Nizip Faculty of Education, Gaziantep, Turkey. 
Mıknatıs hastaneler 15 yıldır ABD'de ilgi çekici olmasına rağmen, etkinliklerine ilişkin araştırma temeli olarak sınırlıdır, çünkü kısmen farklı çalışmalar farklı metodolojileri benimsemiştir ve hastanelerin örneklem popülâsyonu değişmiştir. Mıknatıs hastaneler, ilk olarak ABD'de tanımlanmıştır. 1980'lerin başından itibaren, hem büyüklük hem de organizasyonel özellikleri açısından değişiklikler göstermektedir. Daha yeni araştırmalar, daha sağlam bir metodolojik yaklaşımı temsil etmektedir.

\section{TÜRKIYYE'DEKİ ANKET}

Türkiye'de yürütülen çalışmada, 2019 ile 2020 yılları arasında 32 hastanede çalışan hemşirelere anket uygulaması yapılmıştır. Çalışmanın metodolojik yaklaşımı başka bir yerde verilmemiştir(Aiken vd.,1997).,Hastane örneği Türkiye’nin yedi bölgesinin dördünden alınmıştır ve sadece iyi bir standartta (başka bir kurum tarafından yönetilen)hasta sonuç verilerine sahip olduğu bilinen hastaneler seçilmiştir. Toplamda, tıbbi ve cerrahi ortamlarda çalışan personellerden, 10.022 hemşireye ulaşılmıştır. Whitley pay ölçeğinde $\mathrm{D}, \mathrm{E}$ veya $\mathrm{F}$ dereceleri veya eşdeğeri araştırılmıştır(Walby vd.,1994). Araştırmanın sonucunda anketlere 5006 sağlık personeli yanıt vermiştir. $\mathrm{Bu}$ durum, anketlere \%50 oranında hemşirelerin katıldığını ve yanıt verdiğini göstermektedir. Kullanılan anket sayfa sayısı 12 olup, çalışmaya katılan araştırma grupları tarafından kullanılan standart anketin değiştirilmiş bir versiyonu olarak görülmektedir.

Çalışmanın temel bileşenleri tek bir anket kullanımına dâhil edilmiştir. Bunlar:

* Mevcut işin detayları ( sınıf, uzmanlık, çalışma saatleri dahil),

* Hemşire iş yükü indeksinin uyarlanmış bir versiyonu,

* Maslach tükenmişlik envanteri (Maslach vd.,1986),

* İş özellikleri (memnuniyet, rol değişikliği, hastalık yokluğu ve iğne yaralanması),

* Hasta ve hemşirelerin numaraları,

* Katılımcıların öz geçmişi ( yaşı, cinsiyeti, etnik kökeni ve nitelikleri).

Anketin bir parçası olarak, karar verme ile ilgili ek bir bölüm dâhil edilmiştir. Katılımcılardan 21 tanesi hasta bakım ve işleri ile ilgili kararlarında ne ölçüde yer aldıklarını 4 puanlık bir ölçekte (hiç değil, hiç, çok ve çok fazla arasında) derecelendirmişlerdir. Bu durum hemşirelerin, hemşirelik özerkliği hakkındaki algılarına ek olarak karar verme davranışlarının ölçülebilmesi için dâhil edilmiştir.

Çalışma, uygulama ortamını beş temel boyut açısından karakterize etmeye çalışmıştır:

Year 5/ 2021, Volume-5, Issue-2 | WWW.ispecjournal.org 


\section{ISSN 2717-7262 ISPEC Journal of Social Sciences \& Humanities}

$\checkmark$ Hemşirelik özerkliği,

$\checkmark$ Kaynaklar üzerinde kontrol,

$\checkmark$ Doktorlar ile ilişki,

$\checkmark$ Mental yorgunluk,

$\checkmark$ Karar vermedir.

İlk üç boyut, hemşire iş yükü endeksinin alt boyutları ile ölçülmüştür (Aiken vd.,2000). Duygusal tükenmişlik, birçok meslekte yapılan çalışmalarda yaygın olarak kullanılan bir ölçü olan Maslach Tükenmişlik Envanteri'nin bir alt ölçeğidir. Ülkemizde anketlerde yer alan karar verme bölümündeki puanlar, kararlara katılımı gösteren tek bir ölçek oluşturmak üzere toplanmıştır.

\section{VERİ ANALIZİ}

Analiz ilk olarak, beş temel değişken arasındaki ilişkinin doğasını araştırmıştır. Bunların birbirleriyle ilişkili olduğunu(Tablo 1),hemşire ile bakım kalitesini ve hemşire memnuniyetini değerlendirdiğini ortaya çıkarmıştır. Ölçekler arasında anlamlı ilişkiler olduğu gibi, regresyon analizinde diğer ölçekler için alınan puanlar özerklik ölçeği puanlarını tahmin etmek için kullanılmıştır. Daha ileri analizler, hemşirelik özerkliği ölçeğinin, sunulan hizmetin kalitesi ve daha yüksek iş doyumu seviyeleri ile ilgili daha iyi algılarla pozitif yönde ilişkili olduğunu ortaya koymuştur.

Hemşirelik özerkliği ölçeğinin, klinik ortamı tanımlamada çok önemli bir rol oynadığı görülmüş ve Türkiye'de yapılan araştırmalar bunun mıknatıs hastanelerde daha yüksek olduğunu ortaya çıkarmıştır. Fakat, hemşirelik özerkliği ölçeğinin tam olarak neyi ifade ettiği, bir grubun mesleki özerklik yapısı ve ekip çalışması ilkeleriyle nasıl ilişkilendirildiği bilinmemektedir. Sezgisel olarak, ekip çalışması ve özerklik karşıt yapılar olarak görülmektedir. Artan özerklik, bir profesyonel grubun daha fazla kontrole sahip olduğunu gösterirken; ekip çalışması, kararlar üzerindeki kontrol ve gücün paylaşıldığını dolaylı olarak göstermektedir.

Year 5/ 2021, Volume-5, Issue-2 | WwW.ispecjournal.org

1. This study presented orally in the BILTEK International Symposium-IV; held on April 12-13, 2021 at Gaziantep University, Nizip Faculty of Education, Gaziantep, Turkey. 
Tablo1: İş Tatmini ve Bakım Kalitesi Arasındaki Korelâsyonlar

\begin{tabular}{l|l|l|l|l|l|l|l|}
\cline { 2 - 8 } & Özerklik & $\begin{array}{l}\text { Kontrol } \\
\text { Üzerinde } \\
\text { Kaynaklar }\end{array}$ & $\begin{array}{l}\text { İlişkili } \\
\text { Doktorlar }\end{array}$ & Tükenmişlik & $\begin{array}{l}\text { Karar } \\
\text { Yapımı }\end{array}$ & $\begin{array}{l}\text { İş } \\
\text { Memnuniyeti }\end{array}$ & $\begin{array}{l}\text { Algılanan } \\
\text { Bakım } \\
\text { Kalitesi }\end{array}$ \\
\hline Özerklik & - & & & & & & \\
\hline Kontrol & 0.645 & - & & & & \\
\hline $\begin{array}{l}\text { Doktorlarla } \\
\text { İlişki }\end{array}$ & 0.376 & 0.348 & - & & & & \\
\hline Tükenmişlik & -0.378 & -0.455 & -0.219 & - & & & \\
\hline $\begin{array}{l}\text { Karar } \\
\text { Verme }\end{array}$ & 0.336 & 0.212 & 1.25 & -0.094 & - & & \\
\hline $\begin{array}{l}\text { İş } \\
\text { Memnuniyeti }\end{array}$ & 0.415 & 0.437 & 0.238 & -0.504 & 0.159 & - & \\
\hline $\begin{array}{l}\text { Algılanan } \\
\text { Bakım } \\
\text { Kalitesi }\end{array}$ & 0.395 & 0.531 & 0.255 & -0.334 & 0.171 & 0.371 & - \\
\hline
\end{tabular}

Tüm korelâsyonlar anlamlıdır(p<0.001; iki kuyruklu).

Tablo 2: Ekip Çalışması Maddelerinin Ortalama (SD) Puanları

Hemşirelik İş Yükü Endeksi (n = 4681)

\begin{tabular}{|c|c|c|}
\hline $\begin{array}{l}\text { Doktorlar ve hemşirelerin iyi } \\
\text { çalıșma ilișkileri vardır. }\end{array}$ & 3.04 & 0.62 \\
\hline $\begin{array}{l}\text { Hemşireleri destekleyen amirin } \\
\text { yönetimi önemlidir. }\end{array}$ & 2.81 & 0.92 \\
\hline $\begin{array}{l}\text { İyi bir yönetici olan amirin } \\
\text { müdürü ve önderi vardır. }\end{array}$ & 2.85 & 0.98 \\
\hline $\begin{array}{l}\text { Staff hemşireleri } \\
\text { hemşireler ya da uzman hemşire } \\
\text { klinisyenleri ile görüş̧ } \\
\text { firsatları vardır. }\end{array}$ & 2.94 & 0.79 \\
\hline $\begin{array}{l}\text { Hastanenin diğer hastane } \\
\text { bölümleri ile ilişkisi vardır. }\end{array}$ & 2.77 & 0.68 \\
\hline $\begin{array}{l}\text { Hemşire ve doktorlar arasında } \\
\text { çok fazla ekip çalışması vardır. }\end{array}$ & 2.84 & 0.74 \\
\hline $\begin{array}{l}\text { Doktorlar kaliteli tıbbi bakım } \\
\text { verir. }\end{array}$ & 2.75 & 0.69 \\
\hline $\begin{array}{lcrr}\text { Servis } & \text { müdürü } & \text { başka } & \text { bir } \\
\text { doktorla } & \text { çatışma } & \text { çısa } & \text { bile } \\
\text { bayan } & \text { personelin } & \text { kararını } \\
\text { destekler. } & & & \\
\end{array}$ & 3.05 & 0.90 \\
\hline $\begin{array}{l}\text { Hemşireler ile doktorlar } \\
\text { arasında iş birliği vardır. }\end{array}$ & 2.84 & 0.66 \\
\hline $\begin{array}{l}\text { Servis yöneticileri bayan } \\
\text { personeller ile her gün sorun ve } \\
\text { prosedürü görüşür. }\end{array}$ & 2.83 & 0.89 \\
\hline $\begin{array}{l}\text { Kayıtlı hemşireler, sağlık } \\
\text { asistanları ve yardımcıları ile iyi } \\
\text { ilişkiler içerisindedir. }\end{array}$ & 3.32 & 0.70 \\
\hline
\end{tabular}


Katılımcıların, ne ölçüde hem fikir olduklarını veya katılmadıklarını göstermektedir. Her bir maddenin 4 puanlık bir ölçekte mevcut işinde nasıl olduğu belirtilmiştir.

Tablo 3: Ortalama (SD) Ekip Çalışma Puanları

\begin{tabular}{|c|c|c|c|}
\hline \multicolumn{4}{|l|}{ Derece } \\
\hline D & 2.93 & 0.47 & 1667 \\
\hline $\mathbf{E}$ & 2.88 & 0.45 & 2296 \\
\hline $\mathbf{F}$ & 2.99 & 0.45 & 624 \\
\hline \multicolumn{4}{|l|}{ Çalışma Grubu } \\
\hline Tam Zamanlı & 2.93 & 0.47 & 3288 \\
\hline Kısmi Zamanlı & 2.88 & 0.46 & 1380 \\
\hline \multicolumn{4}{|l|}{ Sözleşme Türü } \\
\hline Sürekli & 2.92 & 0.46 & 4532 \\
\hline Geçici & 2.86 & 0.47 & 113 \\
\hline \multicolumn{4}{|l|}{ Vardiya Grubu } \\
\hline Gündüz vardiyası & 2.95 & 0.47 & 555 \\
\hline $\begin{array}{lll}\text { Gündüz } & \text { ve } & \text { Gece } \\
\text { Vardiyası } & & \end{array}$ & 2.92 & 0.45 & 2756 \\
\hline Sadece Gece Vardiyası & 2.76 & 0.48 & 527 \\
\hline \multicolumn{4}{|l|}{ Cinsiyet } \\
\hline Kadın & 2.91 & 0.46 & 4257 \\
\hline Erkek & 2.88 & 0.46 & 407 \\
\hline
\end{tabular}

Tablo4: Hemşire Değişkenlerine Göre Ekip Çalışması Puanları

\begin{tabular}{|l|l|l|l|l|}
\hline \multirow{2}{*}{} & \multicolumn{3}{|c|}{ Ekip Çalışması Ölçeğinde Puan } & \\
\cline { 2 - 5 } & Düşük & Orta & Yüksek & Toplam \\
\cline { 2 - 5 } & $(\leq 2,5)$ & $(2,6-3,25)$ & $(>3,25)$ & \multicolumn{2}{|l|}{} \\
\hline $\begin{array}{l}\text { İş Memnuniyeti } \\
\text { Genel olarak, mevcut işinizden ne kadar memnunsunuz? }\end{array}$ & $81 \%$ & $63 \%=2947)$ \\
\hline Memnunum & $38 \%$ & $63 \%$ & $19 \%$ & $37 \%(\mathrm{n}=1723)$ \\
\hline Memnun Değilim & $62 \%$ & $37 \%$ & $100 \%$ & 4670 \\
\hline Toplam & $100 \%$ & $100 \%$ & 1176 & \\
\hline N & 835 & 2659 & & \\
\hline Pearson $\div \mathbf{2}=\mathbf{7 6 9}, \mathbf{d f}=\mathbf{6}$, sig = 0.000 & & \\
\hline Hemşire olma memnuniyeti & & & \\
\hline
\end{tabular}

\section{Year 5/ 2021, Volume-5, Issue-2 | WWW.ispecjournal.org}




\begin{tabular}{|c|c|c|c|c|}
\hline \multicolumn{5}{|c|}{ Şu anda işinizden bağımsız olarak, hemşire olmaktan ne kadar memnunsuz? } \\
\hline Memnunum & $52 \%$ & $59 \%$ & $73 \%$ & $61 \%(n=2842)$ \\
\hline Memnun değilim & $48 \%$ & $41 \%$ & $27 \%$ & $39 \%(n=1828)$ \\
\hline Toplam & $100 \%$ & $100 \%$ & $100 \%$ & $100 \%$ \\
\hline $\mathbf{N}$ & 837 & 2658 & 1175 & 4670 \\
\hline \multicolumn{5}{|c|}{ Pearson $\div \mathrm{s}=157, \mathrm{df}=6, \mathrm{sig}=0.000$} \\
\hline \multicolumn{5}{|c|}{$\begin{array}{l}\text { Ayrılma niyeti } \\
\text { Mevcut hemşirelik pozisyonunuzdan ayrımayı planlıyor musunuz? }\end{array}$} \\
\hline $\begin{array}{l}\text { Evet, önümüzdeki bir } \\
\text { yıl içinde } \\
\text { planlıyorum }\end{array}$ & $53 \%$ & $40 \%$ & $27 \%$ & $39 \%(\mathrm{n}=1821)$ \\
\hline Hayır planlamıyorum & $47 \%$ & $60 \%$ & $73 \%$ & $61 \%(n=2823)$ \\
\hline Toplam & $100 \%$ & $100 \%$ & $100 \%$ & $100 \%$ \\
\hline $\mathbf{N}$ & 830 & 2640 & 1174 & 4644 \\
\hline \multicolumn{5}{|c|}{ Pearson $\div 2=151, \mathrm{df}=4, \mathrm{sig}=0.000$} \\
\hline \multicolumn{5}{|c|}{$\begin{array}{l}\text { "Düdük çalınırsa" desteklenir } \\
\text { Aşağıdaki durumları bildirdiğinizde yeterli desteği alacağınızdan ne ka } \\
\text { Hasta bakımının profesyonel standartlarını karşılayamıyor musunuz? }\end{array}$} \\
\hline Kendimden eminin & $53 \%)$ & $78 \%$ & $90 \%$ & $76 \%(n=350)$ \\
\hline $\begin{array}{l}\text { Kendimden emin } \\
\text { değilim }\end{array}$ & $47 \%$ & $22 \%$ & $10 \%$ & $24 \%(n=1085)$ \\
\hline Toplam & $100 \%$ & $100 \%$ & $100 \%$ & $100 \%$ \\
\hline $\mathbf{N}$ & 26 & 2613 & 1153 & 4592 \\
\hline \multicolumn{5}{|c|}{ Pearson $\div 2=719, \mathrm{df}=6$, sig $=0.000$} \\
\hline $\begin{array}{l}\text { Ortalama duygusal } \\
\text { tükenmişlik puanı } \\
\text { (yüksek } \\
\text { puanlar daha fazla } \\
\text { tükenmişliği gösterir) }\end{array}$ & 28.7 & 22.8 & 18.8 & \\
\hline
\end{tabular}

Hemşirelik özerkliğinin ve ekip çalışmasının birbiriyle nasıl ilişkili olduğunu belirtmek için, hemşireler ekibin diğer üyeleriyle çalışma ilişkileri hakkındaki görüşlerini özetleyebilmek adına yeni bir değişken göstermiştir. Analizin bir sonraki aşaması aşağıdaki dört soruyu ele almaya çalışmıştır:

Year 5/ 2021, Volume-5, Issue-2 | WWW.ispecjournal.org 
1) Bir ekip çalışması ölçeği oluşturulabilir mi?

2) Daha fazla ekip çalışması ile hangi çalışma ortamı faktörleri ilişkilendirilir?

3) Hemşire sonuçları ve algılanan bakım kalitesi açısından iyi ekip çalışmasının faydaları var $\mathrm{m} 1$ ?

4) Hemşirelik özerkliği ve ekip çalışması birbiriyle nasıl ilişkilidir?

\subsection{Ekip Çalışması ve Hemşirelik Özerklik Ölçeklerinin Oluşturulması}

İlk olarak, bir ekip çalışması ölçeği oluşturulmuştur. Hemşirelik İş Yükü Endeksine (NWI) dâhil edilen maddelerin çoğu, hemşirelerin başkalarıyla çalışma ilişkilerinin yönlerini ele almıştır. Yüz geçerliliğine dayalı olarak, hemşirelerin şu gruplarla ilişkilerini ilgilendiren 11 madde belirlenmiştir: Servis yöneticileri, doktorlar, hemşire yardımcıları / asistanları (yardımcılar), klinik hemşire uzmanları ve diğer hastane bölümleri olarak sıralanmaktadır. Ankette verilen maddeler Tablo 2'de görülmektedir. NWI' deki diğer maddelerde olduğu gibi, katılımcılardan her bir maddenin mevcut hallerinde, ne ölçüde katıldıklarını veya katılmadıklarını belirtmek için 4 puanlık bir ölçek puanı vermeleri istenmiştir.

Maddeler arasındaki korelâsyonlar incelendikten sonra, takım çalışması düzeyini temsil eden tek bir ölçek oluşturmak için 11 bileşen maddesinin ortalama puanı hesaplanmıştır. Bu yeni ölçeğin alfa güvenilirlik puanı 0.81'dir( $\mathrm{Bu}$, NWI türetilmiş ölçek için elde edilen güvenilirlik puanlarından daha yüksektir).

Önceki çalışma, ekip çalışması ölçeğiyle örtüşen iki madde içerdiğinden yeni bir hemşirelik özerkliği ölçeği oluşturulmuştur. Revize edilmiş hemşirelik özerklik ölçeği (0.68 alfa güvenirlik puanı ile) NWI'den aşağıdaki maddeleri içermektedir:

- Hasta bakımı ile ilgili yeni ve yenilikçi fikirlerin desteklenmesi;

- Hemşireliğin kendi uygulamalarını kontrol etmesi;

- Önemli hasta bakımı ve iş kararları verme özgürlüğü;

- Hemşirelik kararına aykırı şeyler yapmak zorunda kalınmaması;

- Tam zamanlı hemşirelerin hastanenin iç yönetimine katılımıdır.

Katılımcılar, ekip çalışma puanlarına göre üç gruba ayrılmıştır: düşük $(<2.5)$, orta (2.6-3.25) ve yüksek (> 3.25).

\subsection{Ekip Çalışmasıyla İlgili Özellikler}

Year 5/ 2021, Volume-5, Issue-2 | WWW.ispecjournal.org

1. This study presented orally in the BILTEK International Symposium-IV; held on April 12-13, 2021 at Gaziantep University, Nizip Faculty of Education, Gaziantep, Turkey. 
İş özelliklerine göre ekip çalışmasının analizi, belirli hemşire gruplarının diğerlerinden daha az ekip çalışması sergilediğini ortaya çıkarmıştır. Tam zamanlı ve yarı zamanlı hemşireler arasında takım çalışması düzeyinde küçük ama anlamlı bir fark bulunmuştur. Tam zamanlı çalışanların \% 27'si yüksek puanlara sahipken, yarı zamanlı personelin \% 21'i daha düşük seviyede puan almıştır (Tablo 3).

\section{Tablo 5: Bakım Kalitesine Göre Ortalama Takım Çalışması Puanları Değişkenler}

\begin{tabular}{lc}
\hline Bakım Kalitesi Değişkenleri & Ortalama Puan \\
\hline Hemşirelik Bakım Hizmeti Sağlanan Servislerde/ Birimlerde Hastalar \\
Düşük & 2.32 \\
Uygun & 2.59 \\
İyi & 2.89 \\
Mükemmel & 3.15 \\
Son Olarak Hastanede Bakım Kalitesinde Değişiklik & 2.73 \\
Kötü & 2.93 \\
Aynı kaldı & 3.12 \\
İyi & 2.71 \\
Hastaların Kendi Başlarına Yönetebileceğinden Emin Taburcu Edildiğinde Bakım \\
Önemli değil & 2.81 \\
Biraz önemli & 2.96 \\
Güvenli & 3.11 \\
Çok güvenli & \\
\hline
\end{tabular}

Gece vardiyaları, çalışanların \% 28'ine kıyasla gece vardiyalarında sürekli çalışan personelin yalnızca\% 16'sı ile daha düşük ekip çalışması puanları (2,76'ya karşı 2,95) ile ilişkilendirilmiştir. Sözleşme türüne (kalıcı ve kısa vadeli), servis/birimin uzmanlığına, vardiya uzunluğuna veya iş unvanına göre önemli farklılıklar bulunmamaktadır.

$\mathrm{Bu}$ bulguların etkilerinin neler oldukları ve işverenlerin gece personeli gibi grupların ekiplere daha tam entegre olmasını nasıl sağlayacaklarını araştırmaya devam etmelidir.

\subsection{Hemşire Sonuç Değişkenlerine Göre Ekip Çalışması}

Ekip çalışması düzeylerinin daha yüksek olduğunu bildiren hemşirelerin de, işlerinden memnun olma ve işlerinde kalmayı planlama olasılıkları anlamlı olarak daha yüksektir. Fakat, tükenmişlik puanlarının daha düşük olduğu görülmektedir ( $\mathrm{p}<0,001$, tablo 4).

\subsection{Ekip Çalışması ve Hemşire Bakım Kalitesinin Değerlendirilmesi}

Anketteki üç soru kalite sorunlarına yöneliktir. Katılımcılara servislerinde/birimlerinde hastalara verilen hemşirelik bakımının kalitesini nasıl tanımlayacakları sorulmuştur (mükemmel, iyi, orta veya kötü). Hastanelerindeki bakım kalitesinin geçen y1l iyileşip

Year 5/ 2021, Volume-5, Issue-2 | WWW.ispecjournal.org

1. This study presented orally in the BILTEK International Symposium-IV; held on April 12-13, 2021 at Gaziantep University, Nizip Faculty of Education, Gaziantep, Turkey. 
iyileşmediği, aynı kalıp kalmadığı veya kötüleşip kötüleşmediği de sorulmuştur. Üçüncü bir soru hemşirelere, hastalarının hastaneden taburcu olduklarında bakımlarını yönetebileceklerinden ne kadar emin oldukları sorulmuştur.

Ekip çalışması puanları, bu kalite ölçütlerinin her birinde hemşireler arasında önemli ölçüde farklılık göstermiştir. Tablo 5, her bir değişkendeki ortalama takım çalışma puanlarını karşılaştırmaktadır ve tablo 6'da, her değişkenin takım çalışmasına göre çapraz tablolaşmasından elde edilen sonuçların bazılarını göstermektedir ( $\mathrm{p}$ değerlerinin tümü $<0.001)$.

\subsection{Takım Çalıșması ve Özerklik}

Analiz, ekip çalışması ve özerkliğin birbiriyle önemli ölçüde ilişkili olduğunu göstermektedir (0.64, p <0.01). Ekip çalışması düzeyi daha yüksek olan hemşirelerin de daha yüksek özerklik düzeyleri vardır ve karar verme sürecine daha fazla dâhil olmuşlardır. İlişki, Şekil 1'de gösterilen dağılım grafiğinde tasvir edilmiştir.

Basit olması için, hem özerklik ölçeği hem de ekip çalışması ölçeğinin puanları üç seviyeye ayrılmıştır. Böylece, takım çalışması puanı yüksek olanların \%31'i aynı zamanda yüksek özerklik grubunda yer alırken, düşük takım çalışması puanına sahip olanların sadece \%1'i yüksek özerklik puanına sahiptir. Bu nedenle, karşıt olmak bir yana, analiz ekibin diğer üyeleriyle iyi çalışmanın, bir hemşire olarak profesyonel özerklikle hareket edebilme ile güçlü bir şekilde ilişkili olduğunu öne sürüyor gibi görünmektedir. Bu ilişkinin yönünü belirlemek mümkün olmasa da, sonuçlar iki yapı arasındaki yakın ilişkiyi göstermektedir. Ekip çalışması, ilgili personel profesyonel özerkliğe sahip olduğunda etkili olabilir. Tam tersi, hemşireler ekibin diğer üyeleriyle iyi ilişkiler kurduklarında, karar verme sürecine tam olarak dâhil olma ve profesyonel özerklikle hareket etme konusunda daha iyi konumda da bulunabilir. Hemşire özerkliği ile ekip çalışması arasındaki nedenselliğin yönünü belirlemenin zorluklarına ek olarak, kesitsel bir anketteki korelâsyonlardan nedensellik çıkarımına ilişkin daha temel bir sorun vardır; örneğin, korelâsyonlar, daha özellikli tüm bileşenlerin olumlu raporlanmasına yol açan kişinin çalışmasından pozitif memnuniyetin özellikli olmayan bir etkisinden kaynaklanabilir.

Year 5/ 2021, Volume-5, Issue-2 | www.ispecjournal.org

1. This study presented orally in the BILTEK International Symposium-IV; held on April 12-13, 2021 at Gaziantep University, Nizip Faculty of Education, Gaziantep, Turkey. 
Tablo 6: Hasta Bakım Değişkenlerine Göre Takım Çalışması Puanları

\begin{tabular}{|c|c|c|c|c|}
\hline & $\begin{array}{l}\text { Düşük } \\
(<2.5)\end{array}$ & $\begin{array}{l}\text { Orta } \\
(2.5-3.25)\end{array}$ & $\begin{array}{l}\text { Yüksek } \\
(>3.25)\end{array}$ & Toplam \\
\hline \multicolumn{5}{|c|}{ Genel olarak, servisinizdeki hastalara verilen hemsirelik bakımının kalitesini nasıl tanımlarsınız? } \\
\hline Mükemmel & $13 \%$ & $23 \%$ & $53 \%$ & $29 \%(\mathrm{n}=1339)$ \\
\hline İyi & $49 \%$ & $63 \%$ & $44 \%$ & $55 \%(\mathrm{n}=2591)$ \\
\hline Uygun & $32 \%$ & $13 \%$ & $3 \%$ & $14 \%(\mathrm{n}=653)$ \\
\hline Kötü & $6 \%$ & $1 \%$ & 0.2 & $2 \%(\mathrm{n}=87)$ \\
\hline Toplam & $100 \%$ & $100 \%$ & $100 \%$ & $100 \%$ \\
\hline $\mathbf{N}$ & 836 & 2656 & 1178 & 4670 \\
\hline \multicolumn{5}{|c|}{ Pearson $\div 2=812, \mathrm{df}=6, \mathrm{sig}=0.000$} \\
\hline \multicolumn{5}{|c|}{ Son bir yılda hastanenizde hasta bakımı kalitesinin şu özelliklere sahip olduğunu söyleyebilir misiniz } \\
\hline Gelişti & $9 \%$ & $17 \%$ & $33 \%$ & $20 \%(n=904)$ \\
\hline Az gelişti & $45 \%$ & $55 \%$ & $51 \%$ & $52 \%(\mathrm{n}=2407)$ \\
\hline Gelişmedi & $46 \%$ & $28 \%$ & $16 \%$ & $28 \%(\mathrm{n}=1278)$ \\
\hline Toplam & $100 \%$ & $100 \%$ & $100 \%$ & $100 \%$ \\
\hline $\mathbf{N}$ & 824 & 2607 & 1158 & 4589 \\
\hline \multicolumn{5}{|c|}{ Pearson $\div 2=322, \mathrm{df}=4$, sig $=0.000$} \\
\hline \multicolumn{5}{|c|}{ Kendine güvenen hastalar taburcu edildiğinde kendi bașının çaresine bakabilir mi? } \\
\hline Kendinden emin & $90 \%$ & $95 \%$ & $97 \%$ & $95 \%(n=4294)$ \\
\hline $\begin{array}{l}\text { Kendinden emin } \\
\text { değil }\end{array}$ & $10 \%$ & $5 \%$ & $3 \%$ & $5 \%(\mathrm{n}=247)$ \\
\hline Toplam & $100 \%$ & $100 \%$ & $100 \%$ & $100 \%$ \\
\hline $\mathbf{N}$ & 820 & 2580 & 1141 & 4541 \\
\hline
\end{tabular}

Şekil 1: Ekip Çalışması ve Özerklik Arasındaki İlişkiyi Gösteren Dağılım Grafiği. Ayçiçeğinin Yoğunluğu, Vakaların Yoğunluğunu Temsil Eder.

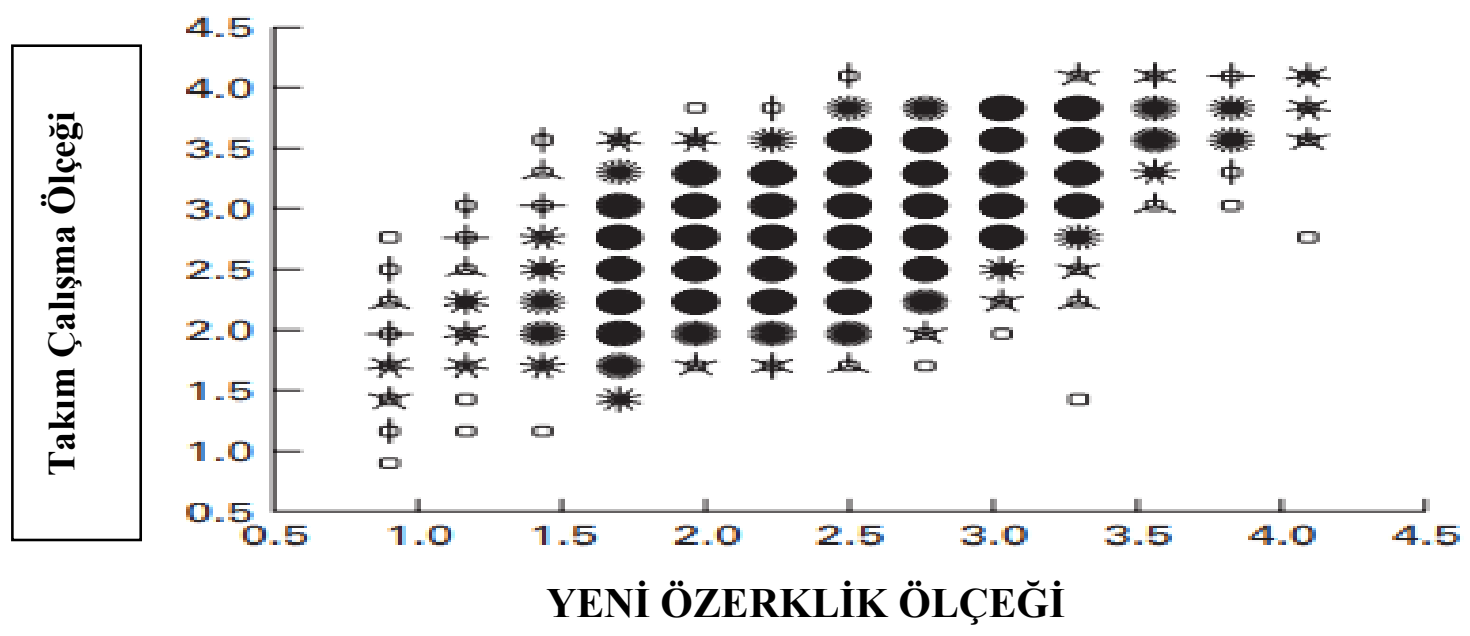

\section{SONUÇ ve ÖNERILLER}

$\mathrm{Bu}$ çalışma, ekip çalışmasının değerini, bunun iş tatmini, hemşire memnuniyeti, görevde kalma süreleri ve rapor edilen tükenmişliğin daha düşük seviyeleri gibi bir dizi olumlu mesleki ve örgütsel özellik ile ilişkisini göstermiştir. Rapor edilen daha yüksek ekip çalışması

Year 5/ 2021, Volume-5, Issue-2 | WWW.ispecjournal.org

1. This study presented orally in the BILTEK International Symposium-IV; held on April 12-13, 2021 at Gaziantep University, Nizip Faculty of Education, Gaziantep, Turkey. 
seviyelerinin, hemşirelerin değerlendirdiği bakım kalitesini de etkilediği görülmüştür. Ekip çalışması ve özerklik arasında güçlü bir ilişki tespit edilmiştir. Ekip çalışmasının özerklik için bir ön koşul mu yoksa tam tersi mi olduğunu belirlemek mümkün değildir, ancak etkileşimleri arasında farklılıklar olduğu kesindir. $\mathrm{Bu}$ nedenle kuruluşlar, ekip çalışmasına zarar verebileceğinden hemşire özerkliğini teşvik etmekten korkmamalıdır.

Karş1lıklılık ve sayg1, "koordineli eylemi kolaylaştırarak toplumun verimliliğini artırabilen güven, normlar ve ağlar gibi sosyal organizasyonun özellikleri" olarak tanımlanan "sosyal sermaye" nin temel taşlarıdır(Putnam vd.,1993). Konuyla ilgili geniş ve büyüyen bir literatürün var olduğu görülmektedir. Siyaset bilimi, sosyoloji ve ekonomi alanında çok fazla çalışma bulunmasına rağmen, sağlık kuruluşlarında yapılan araştırmalar daha kısıtlıdır. Sosyal sermaye açısından zengin kuruluşların, çalışanlar arasındaki yüksek güven seviyesinden yararlandığını ve daha az hiyerarşik olduğunu tahmin edebiliriz. Açıkçası; kavramı, pratik faydasını ve kuruluşlar içinde nasıl işlediğini keşfetmek için daha fazla çalışma yapılması gerekmektedir. Bu tür çalışmalar, örgütsel bağlam, ekip çalışması ve özerklik arasındaki ilişkinin özellikleri ile işleyen mekanizmalara 1şık tutmaya yardımcı olmaktadır. Stacey’nin 1980’lerde Genel Tıp Konseyi’ne ilişkin çalışmasında, ilk kez ifade edilen yeni profesyonellik çağrısı bu durumu destekliyor gibi görünmektedir. Konseyin meslekten olmayan bir üyesi olarak Stacey, doktorların hasta da dâhil olmak üzere diğerlerinin sağlığa katkılarını kabul etmesini ve müttefik meslekler üzerindeki kutsal özerklik ile yargı kavramını değiştirmesi gerektiğini savunmuştur(Stacey, 1992).Stacey'nin savı özünde, kendi kendini düzenlemenin geri çekilmesinden başka bir şey ifade etmemektedir. Profesyonelliğin daha demokratik biçimlerine yönelik çağrılar yeni değildir, ancak birçok sağlık sistemindeki reformun hızı ve yönü, çalışma eğilimini hızlandırabilir (Hugman,1991). Ekip çalışması, gelecekte kurumsal performans ve başarı için giderek daha kritik hale gelecektir.

\section{KAYNAKÇA}

Abbott A. The system of professions: an essay on the division of expert labour. Chicago: University of Chicago Press, 1988.

Aiken LH, Clarke SP, Sloane DM. Hospital restructuring: does it adversely aVect care and outcomes? J Nurs Admin 2000;30:457-65.

Aiken LH, Smith HL, Lake ET. Lower medicare mortality among a set of hospitals known for good nursing care. Med Care 1994;32:771.

Year 5/ 2021, Volume-5, Issue-2 | WWW.ispecjournal.org

1. This study presented orally in the BILTEK International Symposium-IV; held on April 12-13, 2021 at Gaziantep University, Nizip Faculty of Education, Gaziantep, Turkey. 
Aiken LH, Patrician P. Measuring the organizational traits of hospitals: the revised nursing work index. Nurs Res 2000; 49:146-53.

Aiken L. et al. Nurse reports on hospital care in five countries. Health AV 2001;20:43-53.

Aiken LH, Sochalski JA, eds. Hospital restructuring in North America and Europe: patient outcomes and workforce implications. Med Care 1997;35(Supplement).

Aiken LH, Sloane DN, Lake ET, et al. Organization and outcomes of inpatient AIDS care. Med Care 1999;37:760- 72.

Allen D. The changing shape of nursing practice: the role of nurses in the hospital division of labour. London: Routledge, 2001.

Borrill C, West MA, Shapiro D, et al. Teamworking and eVectiveness in health care. Br J Health Care 2000;6:364-71.

Buchan J. Lessons from America? US magnet hospitals and their implications for UK nursing. J Adv Nurs 1994;19: 373.

Carter AJ, West MA. Sharing the burden: teamwork in health care settings. In: Firth-Cozens J, Payne J, eds. Stress in health professionals: psychological and organisational causes and interventions. Chichester: John Wiley, 1999: 191-202.

Casey N, Smith R. Bringing nurses and doctors closer together. BMJ 1997;314:617-8.

Dechairo-Marino AE, Jordan-Marsh M, Traiger G, et al. Nurse/physician collaboration: action research and the lessons learned. J Nurs Admin 2001;31:223-30.

Firth-Cozens J. Celebrating teamwork. Quality in Health Care 1998;7(Suppl):S3-7.

Firth-Cozens J. Multidisciplinary teamwork: the good, bad, and everything in between. Quality in Health Care 2001;10: 65-6

Hugman R. Power in the caring professions. London: Macmillan, 1991.

Irvine D, Sidnia S, McGillis Hall I. Finding value in nursing care: a framework for quality improvement and clinical education. Nurs Econ 1998;16:110-6.

Leatt P, Baker FR, Halverson PK, et al. Downsizing, reengineering and restructuring: longterm implications for healthcare organizations. Frontiers of Health Serv Manage 1997;13:2739.

Maslach C, Jackson SE. Maslach burnout inventory manual. 2nd ed. Palo Alto, California: Consulting Psychologists Press, 1986.

McKee M, Aiken LH, RaVerty AM, et al. Organizationl change and quality of health care: an evolving international agenda. Quality in Health Care 1998;7:37-41.

Year 5/ 2021, Volume-5, Issue-2 | WWW.ispecjournal.org 
Mechanic D, Aiken LH. A cooperative agenda for medicine and nursing. N Engl J Med 1982;307:747-50.

Putnam RD, Leonardi R, Nanetti RY. Making democracy work: civic traditions in modern Italy. Princeton: Princeton University Press, 1993.

RaVerty AM. The politics of nursing knowledge. London: Routledge, 1996.

Shortell SM, Zimmerman JE, Rousseau DM, et al. The performance of intensive care units: does good management make a diVerence? Med Care 1994;32:508-25.

Sochalski J, Aiken LA, Fagin C. Hospital restructuring in the United States, Canada and Western Europe: an outcomes research agenda. Med Care 1997;35:OS13.

Stacey M. Regulating British medicine. The General Medical Council. London: John Wiley, 1992.

Stein LI. The doctor-nurse game. Arch Gen Psychiatry 1967;16:699-703.

Stein LI, Watts DT, Howell T. The doctor-nurse game revisited. N Engl J Med 1990;322:546-9.

Strong P, Robinson J. The NHS under new management. Milton Keynes: Open University Press, 1990.

Traynor M. Managerialism and nursing: beyond oppression and profession. London: Routledge, 1999.

Walby S, Greenwell J, MacKay L et al. Medicine and nursing: professions in a changing health service. London: Sage, 1994.

Wicks D. Nurses and doctors at work: rethinking professional boundaries. Buckingham: Open University Press, 1998.

Zimmerman JE, Rousseau DM, DuVy J, et al. Intensive care at two teaching hospitals: an organizational case study. Am J Crit Care 1994;3:129-38.

Zwarenstein M, Bryant W. Interventions to promote collaboration between nurses and doctors (Cochrane Review) In: The Cochrane Library. Issue 2. Oxford: Update Software, 2001.

Year 5/ 2021, Volume-5, Issue-2 | WwW.ispecjournal.org

1. This study presented orally in the BILTEK International Symposium-IV; held on April 12-13, 2021 at Gaziantep University, Nizip Faculty of Education, Gaziantep, Turkey. 